\title{
Power Input of High-Speed Rotary Impellers
}

\author{
K. R. Beshay, J. Kratěna, I. Fořt, O. Brůha
}

This paper presents the results of an experimental investigation of the power input of pitched blade impellers and standard Rushton turbine impellers in a cylindrical vessel provided with four radial baffles at its wall under a turbulent regime of flow of an agitated liquid. The influence of the geometry of the pitched blade impellers (pitch angle, number of blades) and the off-bottom impeller clearance of both high-speed impellers tested on the impeller power input is determined in two sizes of the cylindrical vessel $(0.3 \mathrm{~m}$ and $0.8 \mathrm{~m}$ diameter of vessel). A strain gauge torquemeter is used in the small vessel and a phase shift mechanical torquemeter is used in the large vessel. All results of the experiments correspond to the condition that the Reynolds number modified for the impeller exceeds ten thousand. The results of this study show that the significant influence of the separating disk thickness of the turbine impeller corresponds fairly well to the empirical equations presented in the literature. Both the influence of the number of impeller blades and the blade pitch angle of the pitched blade impeller were expressed quantitatively by means of the power dependence of the recently published correlations: the higher the pitch angle and the number of blades, the higher the values of the impeller power input. Finally, it follows from results of this study that the impeller off-bottom clearance has a weak influence on the power input of the Rushton turbine impeller, but with decreasing impeller off-bottom clearance the power input of the pitched blade impeller increases significantly.

Keywords: impeller power input, Rushton turbine, pitched blade impeller.

\section{Introduction}

High-speed rotary impellers are generally used for mixing low-viscosity liquids and dispersions under a turbulent regime of flow of an agitated batch [1, 2, 3]. Their main advantage is that they can reduce investment costs for complex gear boxes because their high speed involves transferring the power input from the driving motor to the impeller predominantly via frequency of revolution at a moderate level of torque. The main types of high-speed rotary impellers suitable both for blending pure liquids and for mixing solid-liquid suspensions, gas-liquid dispersions and liquid-liquid emulsions are the standard Rushton turbine impeller (Fig. 1) and the pitched blade impeller (see Figs. 2 and 3). Their design is very well defined and their manufacture is rather simple. The power input of the standard Rushton turbine impeller (SRTI) and pitched blade impellers (PBI) has in many cases of impellers been studied experimentally, and the results of the experiments have been published in dimensionless form by means of similarity criteria [2] a [3]:

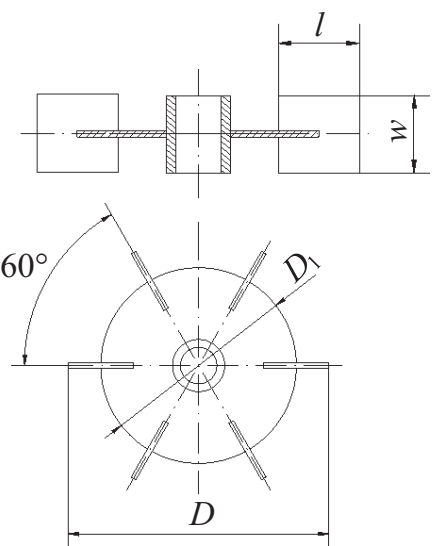

Fig. 1: Sketch of Rushton turbine impeller (Czech standard CVS 691021) $D / \mathrm{T}=1 / 3, w / D=0.2, D_{1} / D=0.75, l / D=0.25$

$$
P o=P o(\operatorname{Re}, \text { geometry of the system })
$$

where the power number

$$
\text { Po }=\frac{P}{\rho n^{3} D^{5}}
$$

and the Reynolds number (modified for impeller)

$$
\operatorname{Re}=\frac{n D^{2} \rho}{\eta} .
$$

The geometry of the agitated system is characterised simplexes of geometric similarity, e.g. $H / T, D / T, D / T, h / \mathrm{T}, n_{\mathrm{B}}$, $b / T, \alpha$ and $t / D$ (see List of Symbols) necessary for scaling up the impeller power input from the pilot plant to industrial size. For Reynolds number greater than ten thousand the power number is independent of this criterion and Eq. (1) can be simplified into the form

$$
P_{0}=P o\left(H / T, D / T, h / T, b / T, n_{\mathrm{B}}, t / D\right)
$$

Published experimental studies have dealt with a quantitative description (usually in the power form) of dependence (4) both for SRTI [3, 4, 5, 6] and PBI [6, 7, 8, 9]. The results of these studies confirm the strong effect of various simplexes of geometric similarity on the impeller power input, e.g., the relative thickness of the turbine separating disc $t / D$ or the pitch angle of the PBI. On the other hand, the experimental studies enable us to neglect the influence of certain simplexes on the impeller power input, e.g. the vessel diameter/impeller diameter ratio $D / T$ of the SRTI or the relative thickness of the blades of the PBI.

The aim of this study is to compare the experimentally investigated power input of the SRTI and PBI determined in two mixing vessels of different sizes under a turbulent regime of an agitated liquid and look for the influence of the main geometric characteristics of the two impellers on the impeller power input. The experimental results will be expressed by means of the above introduced dimensionless variables, and the statistically calculated power correlations will be compared with results published in the literature. 

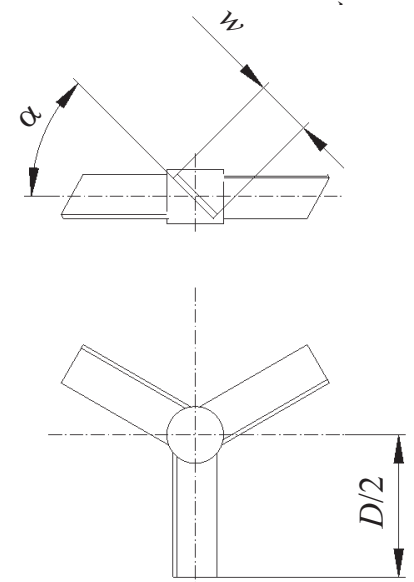

a)
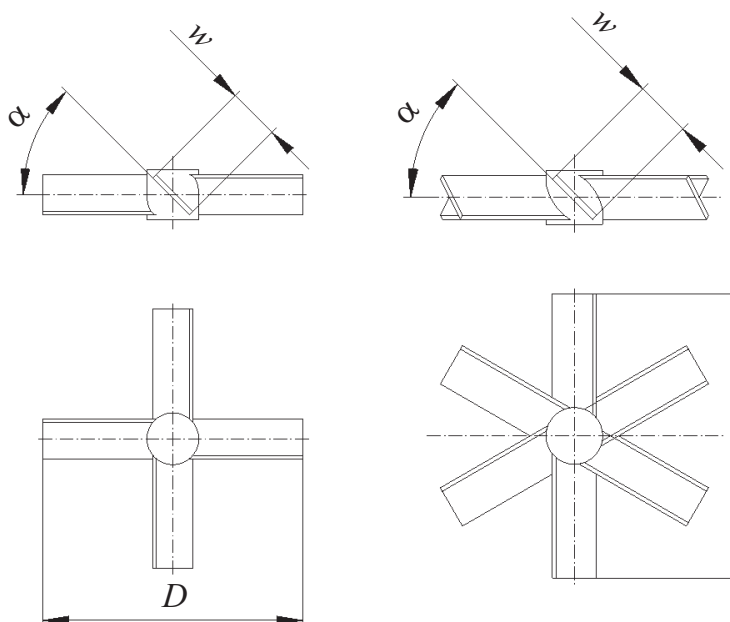

b)

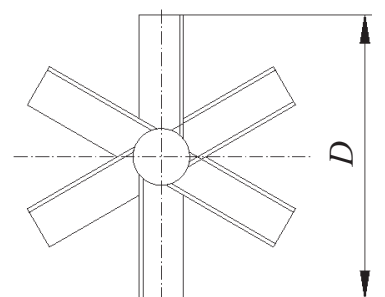

c)

Fig. 2: Sketch of pitched blade impellers (Czech standard CVS 691020) $D / T=1 / 3, w / D=0.2, \alpha=45^{\circ}$

\section{Experimental}

The power input of the SRTI and the PBI was investigated through measurements in two experimental test rigs having the same geometrical parameters as shown in Fig. 3. The first (larger) test rig, shown in Fig. 4, had a flat-bottom cylindrical vessel $0.8 \mathrm{~m}$ in diameter, made of Perspex and equipped with four equally-spaced baffles mounted on the wall and with a width of $b=0.1 \mathrm{~T}$. The working fluid used throughout the measurements was water, at a temperature of $20^{\circ} \mathrm{C}$, whose height $H$ was equal to the vessel diameter $T$. The torque was

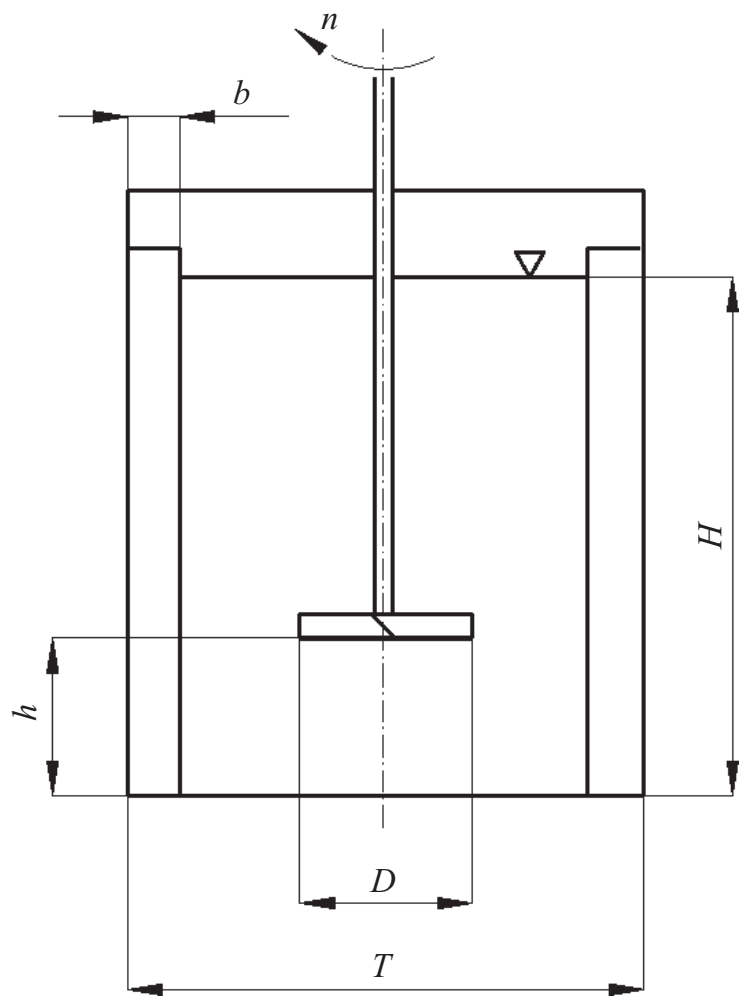

Fig. 3: Geometrical parameters of the agitated vessel. $(H / T=1$, $b / T=0.1, D / T=1 / 3)$ measured by a phase-shift mechanical torquemeter whose output, in the form of an electrical signal, was fed to a data acquisition system. The torquemeter was mounted, under the variable-speed driving motor, above the tank. The rotational speed was measured by means of a photoelectric cell and a notched disc mechanism.

In the smaller-size test rig shown in Fig. 5, a flat-bottom, cylindrical vessel with four baffles at its wall, was again used. The vessel had a diameter of $T=0.3 \mathrm{~m}$ and was filled with water at temperature $20{ }^{\circ} \mathrm{C}$ to a height of $H=T$. A strain gauge torquemeter, mounted on the motor shaft, was used to measure the torque, and the signal was fed to a data acquisition system. The rotational speed was measured, as in the case of the larger-size test rig, by a photoelectric mechanism.

Table 1 shows the geometrical details of the impellers used in this study. For the large-vessel test rig three impellers were investigated, namely: a standard Rushton turbine impeller (SRTI), a 6-blade pitched blade impeller with blade angle $\alpha=45^{\circ}$ (6PBI45) and a 4-blade pitched blade impeller with $\alpha=45^{\circ}$ (4PBI45). For the small-vessel test rig, two types of impellers were investigated. These were the Rushton turbine impeller (SRTI) and pitched blade impellers with the following geometry: 6 blades and pitch angle $\alpha=45^{\circ}$ (6PBI45), 4 blades, $\alpha=45^{\circ}$ (4PBI45), 4 blades, $\alpha=30^{\circ}$ (4PBI30), 4 blades, $\alpha=20^{\circ}$ (4PBI20), 3 blades, $\alpha=45^{\circ}$ (3PBI45), 3 blades, $\alpha=35^{\circ}$ (4PBI35) and 3 blades, $\alpha=24^{\circ}$ (4PBI24). All had a relative diameter $D / T=0.33$.

All experiments were made at three levels of off-bottom clearance, namely: $h / T=0.2,0.35,0.5$ except for the SRTI, where measurements were made at only two off-bottom clearances: $h / T=0.33$ and 0.5 . The off-bottom clearance was measured from the bottom of the vessel to the lower edge of the impeller using a ruler, with a precision of $\pm 1 \mathrm{~mm}$. The error in measuring the blade angle of the pitched blade impellers can be considered $\pm 1^{\circ}$.

A sufficiently wide range of Reynolds number was obtained by varying the rotational speed of the impeller $(n)$. This quantity was kept constant during measurements to within $\pm 2 \mathrm{rpm}$. Therefore, the maximum experimental error 


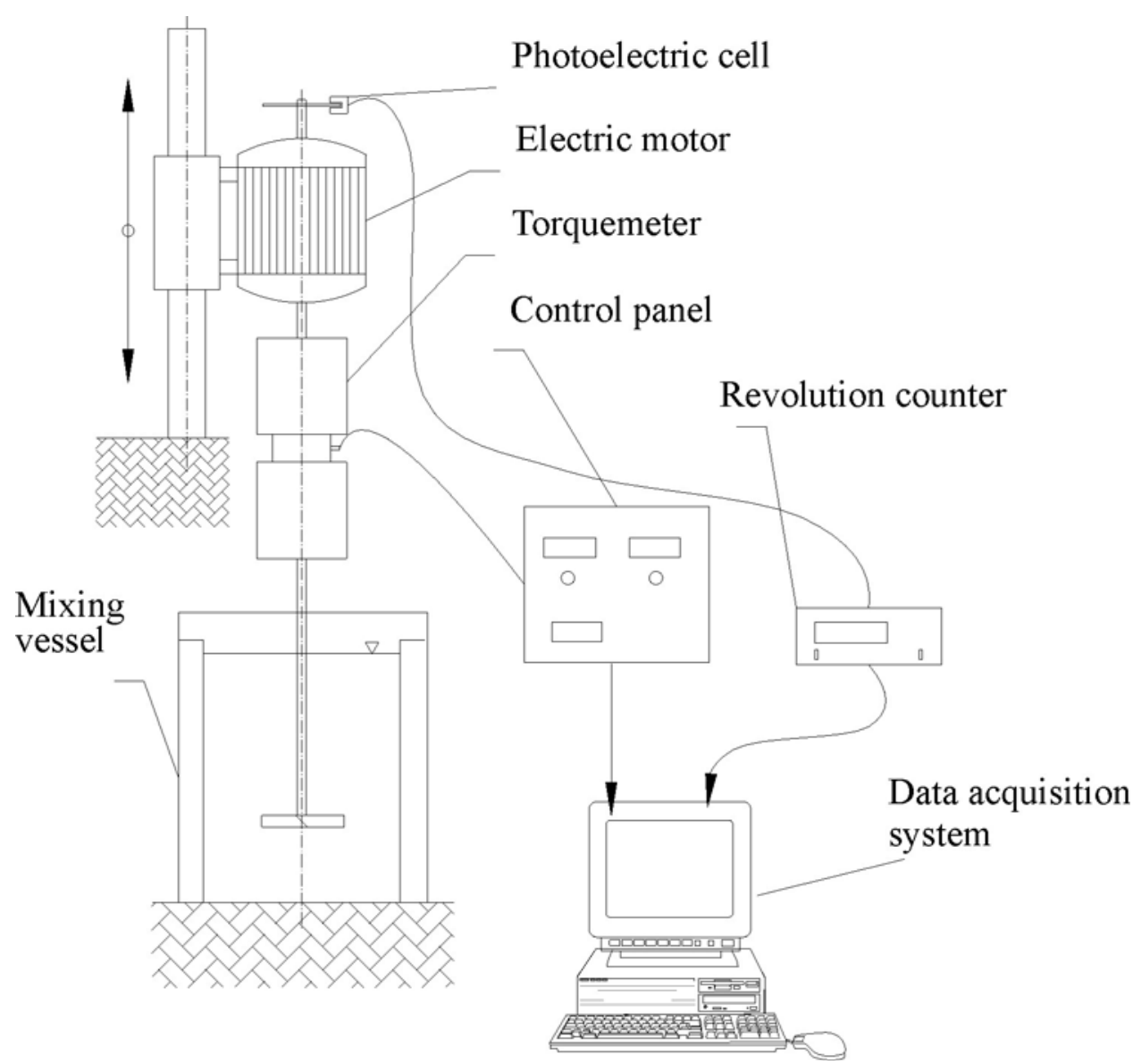

Fig. 4: Layout of the large size test rig

Table 1: Geometrical specifications of impellers

\begin{tabular}{|c|c|c|c|c|c|c|c|c|c|}
\hline & Impeller & $t[\mathrm{~mm}]$ & $D[\mathrm{~mm}]$ & $D / T$ & $l / D$ & $w / D$ & $D_{1} / D$ & $n_{\mathrm{B}}$ & $\alpha[\mathrm{deg}]$ \\
\hline \multirow[t]{3}{*}{ Large vessel } & STRI & 2.50 & 260 & 0.33 & 0.25 & 0.2 & 0.75 & 6 & 90 \\
\hline & $6 \mathrm{PBI} 45$ & - & 255 & 0.32 & - & 0.2 & - & 6 & 45 \\
\hline & 4PBI45 & - & 260 & 0.33 & - & 0.2 & - & 4 & 45 \\
\hline \multirow[t]{8}{*}{ Small vessel } & SRTI & 1.55 & 100 & 0.33 & 0.25 & 0.2 & 0.75 & 6 & 90 \\
\hline & $6 \mathrm{PBI} 45$ & - & 100 & 0.33 & - & 0.2 & - & 6 & 45 \\
\hline & $4 \mathrm{PBI} 45$ & - & 100 & 0.33 & - & 0.2 & - & 4 & 45 \\
\hline & 4PBI30 & - & 100 & 0.33 & - & 0.2 & - & 4 & 30 \\
\hline & 4PBI20 & - & 100 & 0.33 & - & 0.2 & - & 4 & 20 \\
\hline & 3PBI45 & - & 100 & 0.33 & - & 0.2 & - & 3 & 45 \\
\hline & 3PBI35 & - & 100 & 0.33 & - & 0.2 & - & 3 & 35 \\
\hline & 3PBI24 & - & 100 & 0.33 & - & 0.2 & - & 3 & 24 \\
\hline
\end{tabular}

encountered in measuring speed reached $2 \%$ for low Reynolds numbers ( $n=200 \mathrm{rpm}$ ), while this error fell to less than $0.25 \%$ for higher Reynolds numbers ( $n=1000 \mathrm{rpm}$ ).

The main factors affecting the accuracy of the impeller power input measurements were the static and dynamic frictions. The static friction effect was reduced to its minimal value by using a proper bearing and driving motor. The most dominant factor, i.e., the dynamic friction, was closely monitored during the experiment to ensure that steady state values of the torque were recorded. For this purpose, the motor was allowed to run before each set of experiments at high speed (1000 rpm) for one hour, in order to reach the working temperatures of the bearings and motor. The motor was then set to the lowest speed for the particular impeller and allowed to run for 5 minutes till steady state conditions prevailed. Passive torque (torque readings without installing the impeller) was then recorded for 3 minutes. Then the speed was increased by an increment of $40 \mathrm{rpm}$ and the passive torque was recorded again for 3 minutes, and so on until the maximum allowable rotational speed was reached. The motor was then stopped and the impeller was attached and positioned at an off-bottom clearance level. The motor started once again at 


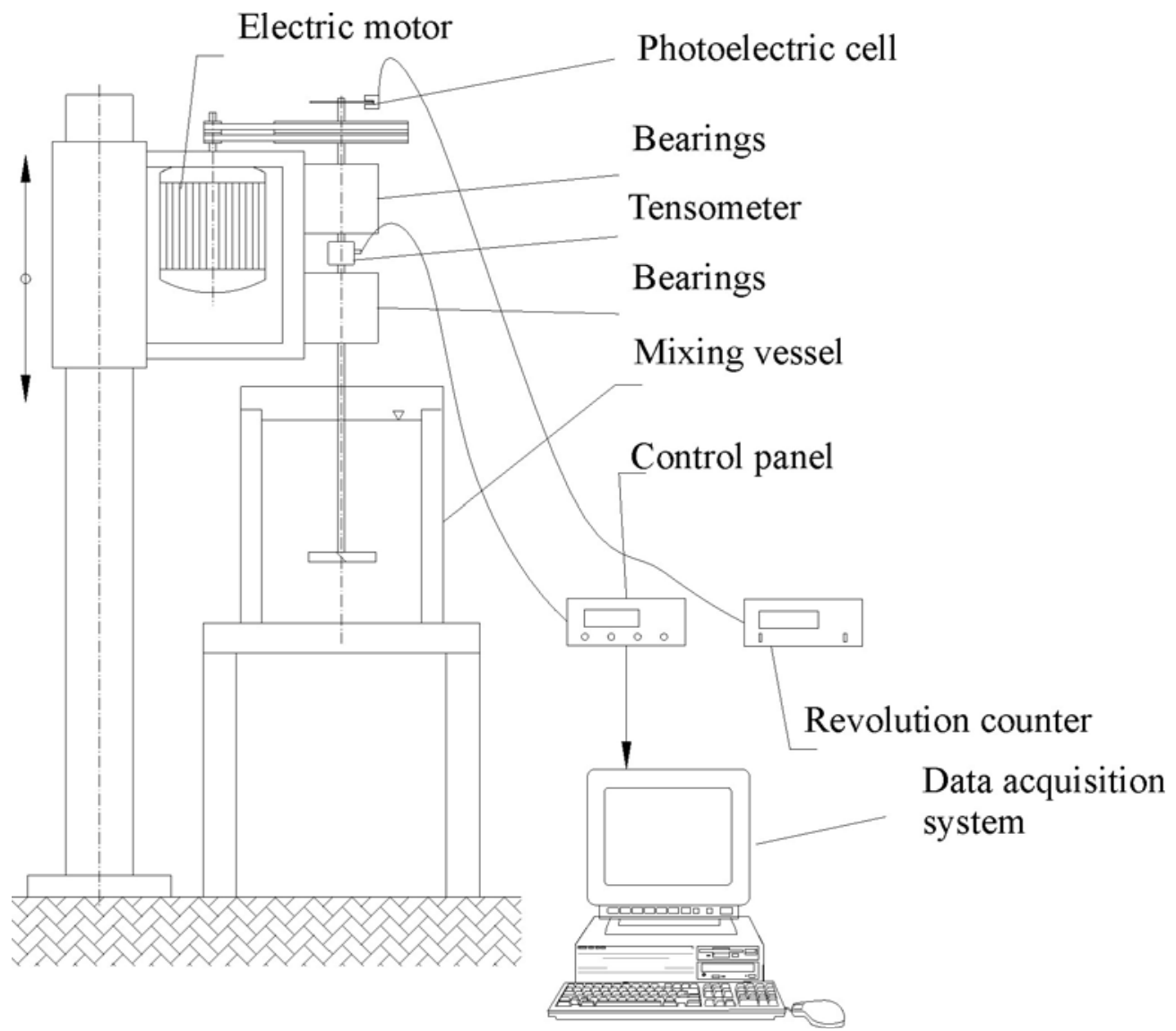

Fig. 5: Layout of the small size test rig

the lowest measuring speed and was left for 5 minutes before recording the torque. Torque data was then collected for 5 minutes, and three collections were recorded at each speed and off-bottom clearance to obtain the average power input. The passive torque was measured once again at the end of each speed range.

This experimental technique was repeated for each impeller and at each off-bottom clearance for both test rigs. The average power number of each impeller across a speed range was then calculated. The average relative standard deviation was calculated and found to be in the range 2.3-16\%. This experimental methodology was adopted to completely eliminate the dynamic resistance of the equipment.

\section{Results and Discussion}

The mean power number defined as the average power number across the speed range of the impeller (from low speed to the speed at which aeration occurs) was measured by

Table 2: Average values of $P_{0}(T=0.8 \mathrm{~m})$

\begin{tabular}{|c|c|c|c|}
\hline \multirow{2}{*}{ Impeller } & \multicolumn{3}{|c|}{ Power Input Measured at } \\
\hline \multirow{2}{*}{ SRTI } & \multicolumn{2}{|c|}{$h / T=0.33$} & \multicolumn{2}{c|}{$h / T=0.5$} \\
\cline { 2 - 4 } & 6.51 & \multicolumn{2}{c|}{6.32} \\
\hline & $h / T=0.2$ & $h / T=0.35$ & $h / T=0.5$ \\
\hline 6PBI45 & 1.63 & 1.52 & - \\
\hline 4 PBI45 & 1.48 & 1.31 & 1.20 \\
\hline
\end{tabular}

the large vessel test rig. The results for the three impellers investigated are reported in Table 2 , at the above mentioned off-bottom clearances. The corresponding results obtained using the small vessel test rig are given in Table 3 for the eight impellers studied.

Table 3. Average values of $P o(T=0.3 \mathrm{~m})$

\begin{tabular}{|c|c|c|c|}
\hline \multirow{2}{*}{ Impeller } & \multicolumn{3}{|c|}{ Power Input Measured at } \\
\hline \multirow{2}{*}{ SRTI } & \multicolumn{2}{|c|}{$h / T=0.33$} & \multicolumn{2}{c|}{$h / T=0.5$} \\
\cline { 2 - 4 } & $h / T=0.2$ & $h / T=0.35$ & $h / T=0.5$ \\
\hline 6PBI45 & 1.84 & 1.69 & 1.55 \\
\hline 4PBI45 & 1.44 & 1.28 & 1.22 \\
\hline 4PBI30 & 0.71 & 0.64 & 0.59 \\
\hline 4PBI20 & 0.32 & 0.29 & 0.28 \\
\hline 3PBI45 & 1.16 & 1.04 & 0.97 \\
\hline 3PBI35 & 0.75 & 0.69 & 0.65 \\
\hline 3PBI24 & 0.39 & 0.36 & 0.33 \\
\hline
\end{tabular}

The experimental results for the SRTI obtained by the large test rig where the Reynolds number was in the range $1.5 \cdot 10^{5}<\operatorname{Re}<3 \cdot 10^{5}$ and those obtained using the small test rig in the range $3 \cdot 10^{4}<\operatorname{Re}<6 \cdot 10^{4}$ show more or less constant power input over Reynolds number range. Only a $4 \%$ change of $P_{0}$ is observed in the recorded date, in accordance 
with [3], although a change of $10 \%$ [5] and even larger changes [6] have been reported. Another significant result obtained from Tables 2 and 3 is that the power input of SRTI varies very slightly (almost constant) with off-bottom clearance. Only a change of $3 \%$ is observed in Po due to change of $C / T$ from 0.33 to 0.5 . This agrees well with the literature [3, 9].

Now, the power inputs of the present study are compared with those obtained from the empirical correlation proposed by Bujalski et al [4], relating the power number to the relative blade thickness $(t / D)$ and the vessel diameter, via:

$$
P_{0}=2.512\left(\frac{t}{D}\right)^{-0.195}\left(\frac{T}{T_{0}}\right)^{0.063},
$$

where $T_{0}=1 \mathrm{~m}$. Good agreements are obtained, e.g., for the large test rig $P_{0}=6.2$ compared to an averaged value of 6.4 of the present study, and for the small test rig the agreement is even better, i.e., $P_{0}=5.3$ compared for 5.425 for the present work. Similar findings were also reported by Rutherford et al [5].

The effect of the off-bottom clearance was investigated in the present work for the pitched blade impellers in both the large and small vessel test rigs. It is clear from the values reported in Tables 2 and 3 that $P o$ decreases, as expected, with increasing $h / T$, in agreement with previous investigation [7]. As the pitched blade impellers pump the flow downwards, it creates a region with large turbulence underneath it. For the smaller bottom clearances, the fluid velocities in the region bounded by the vessel bottom and the impeller are higher, and thus higher friction and higher rate of mechanical energy dissipation are generated, which leads to higher power numbers. For higher off-bottom clearances, lower turbulence leads to lower power numbers.

The effect on power input of the number of blades of the pitched blade impeller at $\alpha=45^{\circ}$ and the effect of changing $\alpha$ at $n_{\mathrm{B}}=4$ and 3 were also investigated in the present work at different off-bottom clearances. The power input data are depicted in Table 3. These and other data for the pitched blade impeller were used to obtain a correlation in the form:

$$
P_{0}=0.996 n_{B}^{0.682}\left(\frac{h}{D}\right)^{-0.178}(\sin \alpha)^{1.995} .
$$

This formula correlates the power input of the pitched blade impeller to the different parameters investigated. The average error (difference between the measured values and those obtained from the correlation) was found to be $1.49 \%$. This correlation can be compared with a similar general correlation found by Medek [7] given in the form:

$$
P o=1.507 n_{B}^{0.701}\left(\frac{h}{D}\right)^{-0.165}\left(\frac{T}{D}\right)^{-0.365}\left(\frac{H}{T}\right)^{0.140}(\sin \alpha)^{2.077}(7)
$$

which was reduced, according to the present geometry, i.e., $T / D=3$ and $H / T=1.0$, to the form:

$$
\text { Po }=1.0092 n_{B}^{0.701}\left(\frac{h}{D}\right)^{-0.165}(\sin \alpha)^{2.077}
$$

A close inspection of Eq. (6) and Eq. (8) reveals that the present results correlate well with those of Medek [7]. In fact the two correlations are almost identical since the variation in the constant and the various exponents are negligibly small.

\section{Conclusions}

The power input of the pitched blade impellers and the standard Rushton turbine impellers were investigated using two cylindrical vessels of different diameters. The effect of several parameters including the vessel diameter, the off-bottom clearance, the number of blades of the pitched blade impellers and the pitch angle were studied. It has been found, for SRTI, that Po remains almost constant over the tested Reynolds number range and it also remains constant at off-bottom clearances greater than $1 / 3$.

A correlation relating the power input of the pitched blade impeller to the number of blades, off-bottom clearance and the pitch angle was obtained from the measured data and compared with the corresponding correlation and good agreement was obtained.

\section{Acknowledgement}

This research has been subsidised by Research Project of the Ministry of Education of the Czech Republic J04/98: 212200008.

\section{List of Symbols}

$b \quad$ baffle width, $\mathrm{m}$

D impeller diameter, $\mathrm{m}$

$h \quad$ off-bottom clearance, $\mathrm{m}$

$H \quad$ total liquid depth, $\mathrm{m}$

$l \quad$ width of Rushton turbine discs, $\mathrm{m}$

$n \quad$ rotational speed, $\mathrm{rps}$

$n_{\mathrm{B}} \quad$ number on blades

$P \quad$ power required by the impeller, $\mathrm{W}$

$P o \quad$ power number

Re Reynolds number

$t \quad$ thickness of Rushton turbine disk, $\mathrm{m}$

$T \quad$ vessel diameter, $\mathrm{m}$

$w \quad$ height of blades, $m$

$\alpha \quad$ pitch angle, ${ }^{\circ}$

$\mu \quad$ dynamic viscosity of agitated liquid, Pa.s

$\rho \quad$ density of agitated liquid, $\mathrm{kg} / \mathrm{m}^{3}$

\section{References}

[1] Holland, F. A.. Chapman, F. S.: Liquid Mixing and Processing in Stirred Tanks. New York, Reinhold Publ. Corp., 1966

[2] Nagata, Sh.: Mixing Principles and Applications. Tokyo, New York, Kodansha Ltd., John Wiley and Sons, 1975

[3] Strek, F.: Mixing and Mixing Equipment (in Czech). Prague, SNTL, 1997

[4] Bujalski, W., Nienow, A. W., Chatwin, S., Cooke, M.: The Dependency on Scale of Power Numbers of Rushton Disk Turbine. Chem. Eng. Sci., 42 (2), 1987, pp. 317-326

[5] Rutherford, K., Mahmoudi, S. M. S., Lee, K. C., Yianneskis, M.: The Influence of Rushton Impeller Blade and Disk Thickness on the Mixing Characteristics of Stirred Vessel. Trans. Inst. Chem. Engrs., 74 (part A), 1996, pp. 369-378 
[6] Chapple, D., Afacan, A., Kresta, S. K.: The Effect of Impeller and Tank Geometry on Power Number for a Pitched Blade Turbine. Trans. Inst. Chem. Engrs, (in press)

[7] Medek, J.: Power Characteristics of Agitators with Flat Inclined Blades. Int. Chem. Eng., 20 (4), 1980, pp. 664-672

[8] Medek, J.: Hydrodynamic Characteristics of Pitched Blade Impellers (in Czech). Technika v Chemii, 74, 1991, pp. 22-28

[9] Ibrahim, S., Nienow, A. W.: Power Curves and Flow Patterns for a Range of Impellers in Newtonian Fluids: $40<R e<5 \cdot 10^{5}$. Trans. Inst. Chem. Engrs., 73, 1995, pp. $485-491$

Dr. Karam R. Beshay

phone: 002022408223

fax: 002025714185

e-mail: krbeshay@hotmail.com
Mech. Eng. Dept.

Faculty of Engineering

Cairo University

Cairo, Egypt

Ing. Jiří Kratěna

Doc. Ing. Ivan Fořt, DrSc.

phone: +420224352713

fax.: +420224310292

e-mail: fort@fsid.cvut.cz

Department of Process Engineering

Doc. Ing. Oldřich Brůha, CSc.

Department of Physics

Czech Technical University in Prague

Faculty of Mechanical Enginering

Technická 4, 16607 Praha 6, Czech Republic. 